\title{
Editorial
}

\section{Advanced Cementitious Building Materials with Applications in Civil Engineering}

\author{
Peng Zhang, ${ }^{1}$ Song Han, ${ }^{2}$ Serina $\mathrm{Ng}^{3}$ and Xu-Hao Wang ${ }^{4}$ \\ ${ }^{1}$ School of Water Conservancy and Environment Engineering, Zhengzhou University, Zhengzhou 450001, China \\ ${ }^{2}$ School of Civil Engineering, Beijing Jiaotong University, Beijing 100044, China \\ ${ }^{3}$ Department of Materials and Structures, SINTEF Building and Infrastructure, 7465 Trondheim, Norway \\ ${ }^{4}$ National Concrete Pavement Technology Center, Iowa State University, Ames, IA 50011, USA
}

Correspondence should be addressed to Peng Zhang; zhangpeng@zzu.edu.cn

Received 13 June 2017; Accepted 13 June 2017; Published 11 July 2017

Copyright (C) 2017 Peng Zhang et al. This is an open access article distributed under the Creative Commons Attribution License, which permits unrestricted use, distribution, and reproduction in any medium, provided the original work is properly cited.

Cementitious building material is most extensively used as a kind of architectural materials in latter day and is the largest artificial material at present. With the high development of construction industry, many building structures with long span, high strength, and great height are being constructed or used under harsh conditions, which has higher requirements on cementitious building materials. Advanced cementitious building materials can be defined as the cementitious building materials that can meet special combinations of properties and uniformity requirements, which cannot always be achieved routinely using traditional raw materials and conventional mixing, placing, and curing methods. The factors which justify the popularity of advanced cementitious building materials are high strength, high workability, and high durability for various structural purposes [1]. Compressive strength of the cementitious material which is usually applied to evaluate the quality of cementitious material and its applicability for purpose is a major component in rational structure design. Today, the durability is also a major aspect to be considered in civil engineering structure design as the importance of durability of cementitious materials is being more and more accepted and emphasized [2]. A large number of investigators are devoting themselves to developments of advanced cementitious building materials and also studying on the mechanism research for peculiar performance, manufacturing technique, experiment methods, modeling, and applications of various advanced cementitious building materials. Generally, there are a lot of approaches to obtain advanced cementitious materials. In general, specific binding materials, aggregates, and additives can be incorporated into the conventional cementitious materials to obtain advanced cementitious materials. For example, some extraordinary aggregates [3], chemical additives [4], various fibers [5, 6], and mineral admixtures $[7,8]$ can be added to fabricate advanced cementitious building materials.

Cementitious building materials have significant new progresses in recent years. The advanced cementitious building materials will provide better materials for specific projects in civil engineering. This special issue aims to bring investigators from industry and academia together to report and explore the new investigations techniques, new preparation methods and basic material properties, testing methods, and standardization in civil engineering, fresh properties and constructability, shrinkage and creep, structural performance and modeling, functional coatings for buildings, durability and sustainability, and field applications in advanced cementitious building materials and review the latest progress in this field. The advanced cementitious building materials include common cementitious composites building materials, cementitious pavement materials, high-performance concrete and ultrahigh-performance concrete, high-ductility and fibre-reinforced materials, and self-sensing/self-healing concrete. Out of about twenty-five submitted manuscripts, six research manuscripts have been selected and published in this special issue because of their good quality and relevance to the theme of this special issue. The selected articles address various aspects, including bond performance between the concrete matrix with different initial crack width and the steel bars with different diameters, mechanical properties of different contents of rubber particles modified cement mortar, 
and experiments and finite element analysis of mechanical properties of steel fiber-reinforced concrete T-beams, punching shear and impact resistance of steel fiber-reinforced slagbased geopolymer concrete, mechanical response of modified Portland cement concrete containing crumb-rubber, and numerical simulations of restrained shrinkage cracking in glass fiber-reinforced shotcrete slabs.

The paper titled "Bond Effects between Concrete and Steel Bar Using Different Diameter Bars and Different Initial Crack Width" is authored by P.N. Faye et al. They conducted the standard pull-out test and distribution of chloride ion test for the bond specimens and measured the bond strength to evaluate the combined effect of different diameter bars embedded in cracked concrete and different initial crack width on the bond properties between concrete and steel bars. In the study, they artificially made four widths of initial crack of $0,80,150$, and 210 microns by inserting slice into bond specimens during the casting of concrete. Besides, they adopted three bar diameters of $10 \mathrm{~mm}, 14 \mathrm{~mm}$, and $18 \mathrm{~mm}$. After being cured for 28 days, the bond specimens were exposed to the environment of wet-dry cycles of seawater and atmosphere for another 90 days. Their results indicate that the cracks with width less than 80 microns for the specimens with $10 \mathrm{~mm}$ diameter embedded bar rapidly disappeared during the course of wet-dry cycles, and the crack width below 150 microns decreased slightly. However, the crack width over 200 microns will increase gradually. The chloride content of the specimens increased with the increase of initial crack width or the diameter of the embedded bar. Furthermore, the chloride content decreased with the increase of concrete depth.

G. Xue and M. Cao conducted a study on the influence of modified rubber particles mixing content on properties of cement mortar. They prepared the cement mortar containing crumb-rubber using the crumb-rubber aggregates in 60 mesh, which have been modified by $1 \%$ polyvinyl alcohol solution. The properties of the cement mortar include compressive strength, impact resistance, flexural strength, the ratio of compressive strength to flexural strength, and dry contraction percentage. In their study, five rubber dosages of $7.5 \%, 15 \%, 19 \%, 22.5 \%$, and $30 \%$ were selected. The optimal content of crumb-rubber was determined by three measured parameters: dry contraction percentage, impact resistance, and the ratio of compressive strength to flexural strength. Their results showed that the ratio of compressive strength to flexural strength has the minimum value when the content of modified rubber particles is $19 \%$. At the same time, the modified mortar exhibits high rational drying shrinkage and high impact resistance with the rubber content of $19 \%$. Therefore, the authors considered $19 \%$ as the optimal used amount of the modified rubber particles in their study.

The paper titled "Experimental Research and Finite Element Analysis on Mechanical Property of SFRC T-Beam" is authored by M. Sun et al. Through a series of experiments of one common concrete T-beam and two steel fiber-reinforced concrete T-beams using two-point loading method, they investigate the effect of different steel fiber volume contents on the ultimate shear capacity, integral rigidity, and the crack distribution characteristics, and the relevant influencing mechanism was analyzed. They also simulated the experiment results obtained using ANSYS software and found that the simulation results of ANSYS were well accordant with the test results. Both of the results of experiments and ANSYS software simulation indicated that the addition of steel fibers greatly increased the ultimate shear capacity and integral rigidity of the concrete, and the propagation of cracks can be partially reduced effectively by the addition of steel fibers. The results also indicate that ANSYS software can be applied to accurately simulate the mechanical properties of steel fiberreinforced T-beam.

S. Karunanithi in the paper titled "Experimental Studies on Punching Shear and Impact Resistance of Steel Fibre Reinforced Slag Based Geopolymer Concrete" carried out a series of punching shear tests and impact tests to evaluate the punching shear and impact resistance of steel fiber-reinforced slag-based geopolymer concrete. The related response of the slag-based geopolymer concrete under shear load and sudden impact load was determined. Besides, the author took the scanning electron microscope (SEM) images for the slag-based geopolymer samples with alkali activators and accelerators and carried out the Energy-Dispersive X-ray Spectroscopy (EDX) analysis on the hardened samples of slag-based geopolymer paste. The various dosages of steel fiber added to the slag-based geopolymer concrete in that study include $0.5 \%, 1.0 \%$, and $1.5 \%$. From the results, it can be found that the slag-based geopolymer concrete with the binder to aggregate ratio of 0.22 and fine to coarse aggregate ratio of 0.6 , reinforced by $1.0 \%$ volume dosage of steel fibers, exhibited higher punching shear force, better energy absorption, and higher first crack toughness and ultimate failure toughness. Within the scope of the fiber dosages in this study, $1 \%$ of steel fiber is the optimal volume content for the slag-based geopolymer concrete to obtain better punching shear and impact resistance.

The paper titled "Influence of Crumb-Rubber in the Mechanical Response of Modified Portland Cement Concrete" is authored by J. Retama and A.G. Ayala. They conducted a series of experiments to study the influence of crumb-rubber on the mechanical properties of Portland cement concrete. In their study, three different contents of crumb-rubber and the Disk-Shaped Compact Tension specimen geometry, normed by the D7313-13 of the ASTM, were used to prepare the concrete. Based on the hypothesis that the stone aggregate replaced with crumb-rubber in the concrete mixture can modify the energy dissipation during the course of cracking process and can affect the concrete properties under monotonically increasing loads, they also carried out the numerical simulations to simulate the damage evolution of the concrete, applying the numerical model of Embedded Discontinuity Method (EDM). Their experiment results indicated that the rubber fineness used in their study has great influence on the fracture energy and other properties of concrete. The numerical simulation results showed that good approximation of the experimental curve in the elastic and softening branches can be provided by using the numerical methods in their study.

A. Sjölander and A. Ansell in the paper titled "Numerical Simulations of Restrained Shrinkage Cracking in Glass Fibre 
Reinforced Shotcrete Slabs" demonstrated a method for nonlinear numerical simulations to study the differences in stress build-up and cracking behavior of restrained shotcrete slabs subjected to shrinkage. Through the numerical simulation, they obtained the influence of the irregular shape and varying thickness on the cracking properties of the shotcrete. By varying the fracture energy in bending and in the interaction between shotcrete and the substrate, the influences of glass fiber reinforcement and bond were obtained in their study. Their results indicated that an end-restrained shotcrete slab was prone to shrinkage-induced cracking, and it is important for the continuous bond to avoid wide shrinkage cracks when shotcrete is sprayed directly onto the rock.

\section{Acknowledgments}

We would like to thank the authors who have submitted manuscripts to this special issue. We would also like to acknowledge the referees who have put in the hard work and their valuable time to review each paper in a timely and professional way. The lead editor thanks all the editors for their contribution in reviewing and assigning reviews for the submitted manuscripts.

$$
\begin{array}{r}
\text { Peng Zhang } \\
\text { Song Han } \\
\text { Serina Ng } \\
X u-H a o \text { Wang }
\end{array}
$$

\section{References}

[1] B. J. Olawuyi and W. P. Boshoff, "nfluence of SAP content and curing age on air void distribution of high performance concrete using 3D volume analysis," Construction and Building Materials, vol. 135, pp. 580-589, 2017.

[2] H.-S. Shi, B.-W. Xu, and X.-C. Zhou, "Influence of mineral admixtures on compressive strength, gas permeability and carbonation of high performance concrete," Construction and Building Materials, vol. 23, no. 5, pp. 1980-1985, 2009.

[3] A. Remadnia, R. M. Dheilly, B. Laidoudi, and M. Quéneudec, "Use of animal proteins as foaming agent in cementitious concrete composites manufactured with recycled PET aggregates," Construction and Building Materials, vol. 23, no. 10, pp. 31183123, 2009.

[4] J. Y. Wang, N. Banthia, and M. H. Zhang, "Effect of shrinkage reducing admixture on flexural behaviors of fiber reinforced cementitious composites," Cement and Concrete Composites, vol. 34, no. 4, pp. 443-450, 2012.

[5] P. Zhang and Q.-F. Li, "Effect of polypropylene fiber on durability of concrete composite containing fly ash and silica fume," Composites Part B: Engineering, vol. 45, no. 1, pp. 1587-1594, 2013.

[6] P. Zhang, Y.-N. Zhao, C.-H. Liu, P. Wang, and T.-H. Zhang, "Combined effect of nano-SiO2 particles and steel fibers on flexural properties of concrete composite containing fly ash," Science and Engineering of Composite Materials, vol. 21, no. 4, pp. 597-605, 2014.

[7] P. Zhang and Q.-F. Li, "Effect of silica fume on durability of concrete composites containing fly ash," Science and Engineering of Composite Materials, vol. 20, no. 1, pp. 57-65, 2013.
[8] P. Zhang, X.-B. Dai, J. X. Gao, and P. Wang, "Effect of nano$\mathrm{SiO}_{2}$ particles on fracture properties of concrete composite containing fly ash," CurrentScience, vol. 108, no. 11, pp. 20352043, 2015 


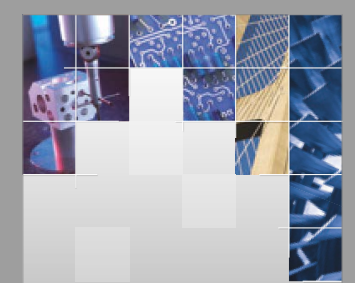

\section{Enfincering}
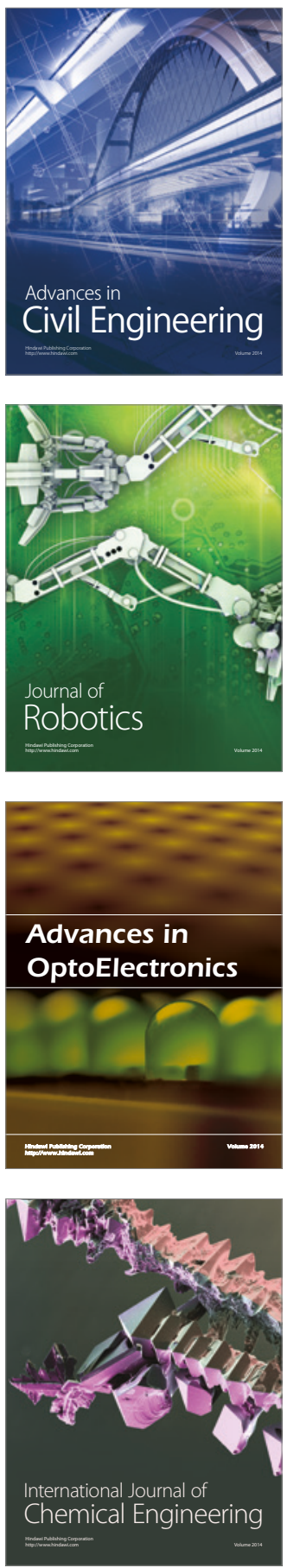

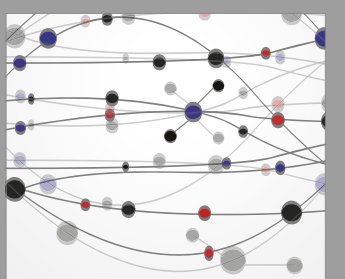

The Scientific World Journal

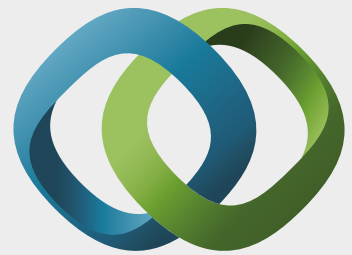

\section{Hindawi}

Submit your manuscripts at

https://www.hindawi.com
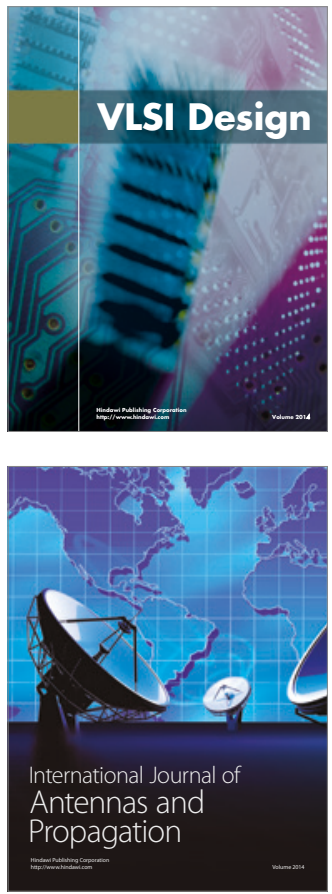

\section{Rotating}

Machinery
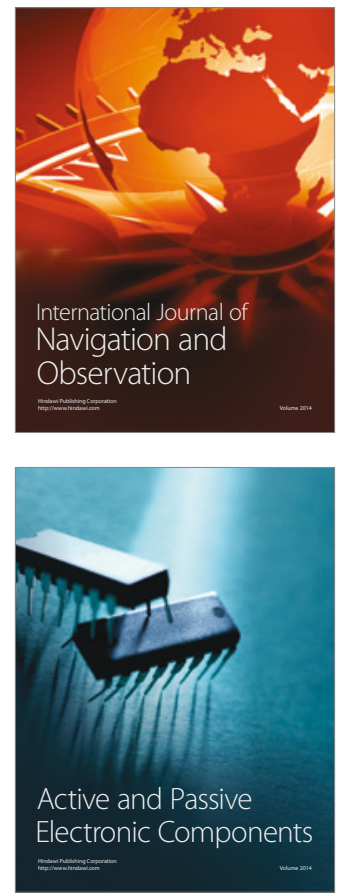
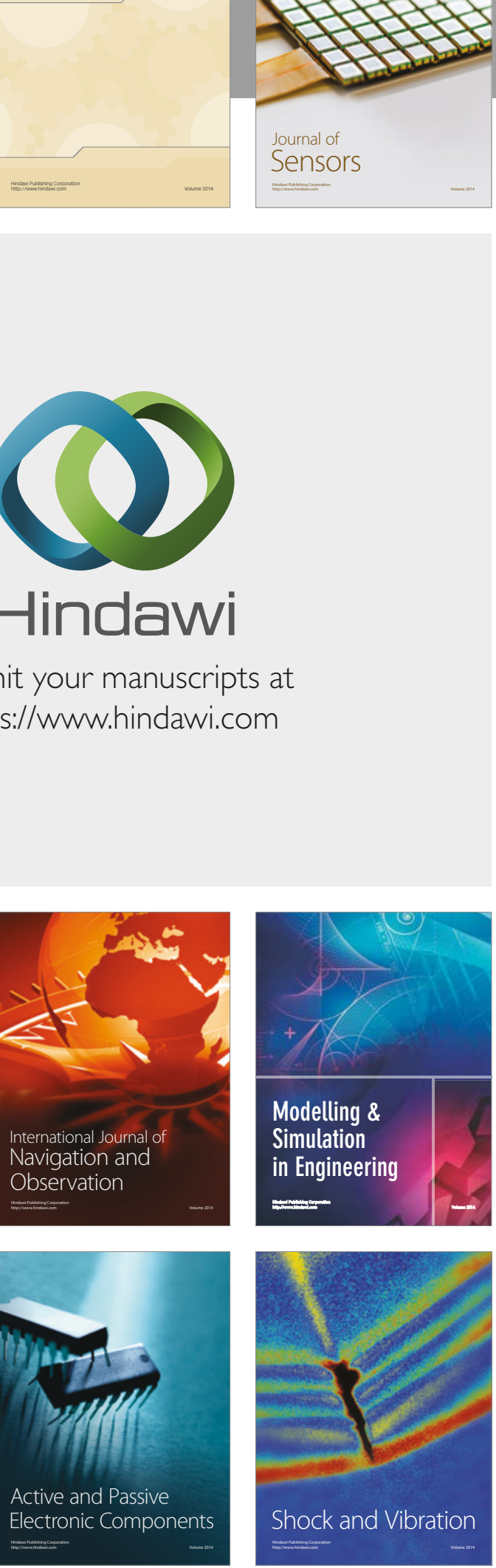
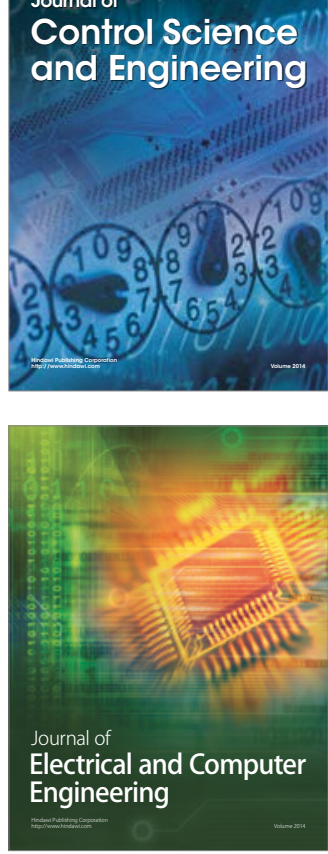

Distributed

Journal of

Control Science

and Engineering
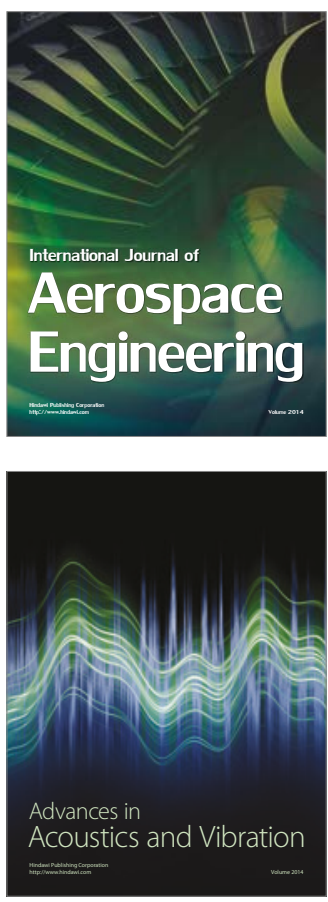

Sensor Networks 